\title{
Realidad y ficción sobre los medios en nuestro mundo neoliberal
}

Enrique Guinsberg ${ }^{1}$

\section{s}

es prácticamente unánime el reconocimiento de la importancia y significación de los medios en los tiempos actuales, incluso mucho mayor al de épocas muy recientes, donde siempre se aceptó su enorme peso, existen marcadas diferencias acerca de sus características y su vínculo-relación con el modelo neoliberal hoy hegemónico, y se percibe la debilidad de un análisis crítico, antes tal vez no dominante pero sí marcado e importante.

Evidentemente es imposible negar o no querer ver el papel que hoy cumplen unos medios omnipresentes - y para algunos también omnipotentes y absolutos- en el funcionamiento político, económico y político de una época signada por la información y la informática, y donde su crecimiento y desarrollo, en particular la de los electrónicos, ya alcanza magnitudes casi inconmensurables y tiene perspectivas poco imaginables, donde la ficción es alcanzada y superada antes de lo pensado. No hace falta ofrecer datos sobre esto ni recordar que hace muy pocos años no existían tecnologías hoy comunes, $o$ al menos generalizadas y de acceso para amplios sectores, y que en un tiempo muy escaso han sido superados los aportes considerados en su momento como novedosos y revolucionarios, dentro de un proceso de cambio con velocidad cada vez mayor y a veces superior a la capacidad de asimilación de una nada desdeñable cantidad de personas.

Todo esto es prácticamente un lugar común, repetido casi hasta el hartazgo y con admiración y sorpresa por quienes todavía tienen alguna capacidad de asombro, no obstante también permite el retorno a fantasías similares, pero modernizadas, a las que hubo en las etapas iniciales del desarrollo de los medios: su importancia para el mejoramiento de los vínculos humanos, los niveles de educación, conocimiento e información en aras de un mayor bie-

1. Universidad Autónoma Metropolitana-Xochimilco, correo electrónico: gbje1567@cueyatl.uam.mx. 
nestar e igualdad en todos los terrenos, etc. Utopías que, rápida o lentamente, fueron vistas como tales por quienes tuvieron que reconocer que, como siempre, un desarrollo tecnológico es valioso no por lo que potencialmente ofrece, sino por el uso que realmente tiene, que estará determinado por la utilización que de él se haga en el contexto del tipo de dominación existente en cada momento histórico. El resto es bastante conocido: el paso a un cuestionamiento que no ha estado limitado a las múltiples variantes de un pensamiento crítico, sino que también existió en todo analista o receptor "integrado" pero con capacidad de ver las características dominantes de unos medios que podían ser lo contrario a lo idealmente deseado y estar al servicio del control social.

Hoy parecería que la historia se repite, no faltando - al contrario, son una importante mayoría - los que están alborozados por el brillante futuro que auguraría el desarrollo tecnológico de unos medios que se ubican como los verdaderos instrumentos de lo mismo que se decía hace muchas décadas y que la realidad demostró que era factible, pero imposibilitado por el manejo concreto de ellos hecho por la absoluta mayoría de los marcos sociales. Aunque ante esta reiteración más de un escéptico recordaría irónicamente lo conocido, que la historia efectivamente puede repetirse, pero la primera vez como drama y la segunda como comedia.

Claro que esta repetición ahora se produce con base en el señalado desarrollo tecnológico, que sin dudas favorece la llegada de los medios a escalas antes imposibles, y sobre todo con un avance cibernético que abre puertas, al menos hasta ahora, a un mundo de libertades prácticamente ilimitado. Pero también, lo que no debe olvidarse son las concepciones vigentes en los sectores del poder de los fines de la "ideología" e incluso de la "historia", lo que permitiría un gran avance de las tecnologías que posibilitarían el logro de libertades nunca vistas hasta ahora y de un progreso incesante para sectores de todo tipo en todos los ámbitos mundiales. La caída del "imperio del mal" (según la terminología reaganiana), la globalización y el considerado avance en la "democratización" mundial facilitarían ahora lo antes dificultado o imposibilitado, aunque la nueva, reciente y temporalmente sin límites "lucha contra el terrorismo" implique algunas trabas para tal objetivo.

Renace entonces la fe esperanzada, pero ya no vista como utopía sino como una tangible realidad fundamentada en hitos centrales, como el hecho de que el señalado desarrollo tecnológico y la modernidad sin frenos permiten un acceso mayor a medios casi sin límites, los que ofrecen una multitud de opciones para que el público, la ciudadanía o los consumidores -según lo que se prefiera como denominaciones no precisamente neutras- puedan elegir de acuerdo a gustos y convicciones, en un panorama libre para que todos puedan expresar sus ideas y difundir lo que quieran sin fronteras geográficas, 
gracias a una tecnología que las evita en la comunicación actual (Internet, televisión satelital, etcétera).

Antes de ver cuánto de esto es realidad y cuánto ficción, es interesante volver a la tan clásica, reiterada como valiosa clasificación de Umberto Eco en apocalípticos e integrados frente a la comunicación de masas, y evaluar su pertinencia actual. Según Eco (1977: 12-13), los segundos surgen

dado que la televisión, los periódicos, la radio, el cine, las historietas, la novela popular y el Reader's Digest ponen hoy en día los bienes culturales a disposición de todos, haciendo amable y liviana la absorción de nociones y la recepción de información, estamos viviendo una época de ampliación del campo cultural, en que se realiza finalmente a un nivel extenso, con el concurso de los mejores, la circulación de un arte y una cultura "popular". Que esta cultura surja de lo bajo o sea confeccionada desde arriba para consumidores indefensos, es un problema que el integrado no se plantea. En parte es así porque, mientras los apocalípticos sobreviven precisamente elaborando teorías sobre la decadencia, los integrados raramente teorizan, sino que prefieren actuar, producir, emitir cotidianamente sus mensajes a todos los niveles. El Apocalipsis es una obsesión del dissenter, la integración es la realidad concreta de aquellos que no disienten.

La clasificación de Eco es contundente y clara, pero ya desde su formulación, que tuvo amplia divulgación y éxito, fue marcadamente dicotómica, necesitada de matices y agregados. El primero de ellos, que siempre hubo, hay y habrá tanto integrados como apocalípticos en el campo de los teorizadores como en el de los ahora llamados "comunicadores", clara expresión de lo cual han sido los teóricos funcionalistas y múltiples más; aunque es cierto que, pero por dificultades del acceso a los medios, sobre todo los electrónicos, los "apocalípticos" han tenido fuertes impedimentos para la divulgación de sus mensajes, por lo que se limitaron fundamentalmente al ámbito académico.

Pero hoy, cuando la vigencia del pensamiento crítico en general y sobre la comunicación en particular está en marcado retroceso frente a otras épocas no muy lejanas, tal como se analizó en un trabajo anterior en estos mismos Anuarios de Investigación (Guinsberg, 2001a) y se reiterará más adelante, ino puede pensarse que en muchos casos ambas categorías de Eco pueden y deben fusionarse para hablar de unos apocalípticos integrados o, si se prefiere, integrados apocalípticos, que plantean una visión irreal y utópica pero, a la inversa de lo sostenido por Eco, en el marco apuntado de fe idílica sobre las posibilidades actuales de la comunicación, y sin ninguna visión crítica, o sea "integrada"? Es cierto que cambia el sentido del primer término, pero la visión apocalíptica se mantiene en su sentido riguroso: como crítica (en una postura casi fundamentalista) en la perspectiva de Eco, y acrítica (muchas veces también fundamentalista) en la aquí apuntada. 
Integrantes de esta nueva (y vieja) categoría están por todos lados: también, como se verá más adelante, desde aquellos que son profetas de una nueva humanidad renacida, liberada y recuperada gracias a la magia comunicativa que todo lo puede, hasta quienes tienen alguna mirada crítica (o que dice que lo es sin serlo seria y realmente) pero están encandilados y por demás subyugados por el encanto de las nuevas tecnologías ante las que se inclinan reverentes o con mínimos cuestionamientos.

Es entonces cuestión de analizar el problema y ver cuánto hay de realidad y cuánto de ficción en el actual mundo comunicativo respecto a lo que ofrece para el crecimiento y enaltecimiento de un desarrollo humano liberador que intensifique el conocimiento, posibilite una real comunicación dialogal, permita elección de verdaderas opciones, facilite el intercambio de propuestas sociales y políticas, y todos los etcéteras conocidos e indicados por los defensores de esta especie de paraíso comunicativo actual y futuro.

Dada la gran cantidad de aspectos intervinientes, sólo podrán verse los ejes estructurales del problema, los que, aunque de alguna manera separados en las páginas siguientes, deben verse como profundamente interrelacionados: la concentración cada vez mayor del control de los medios - sobre todo los electrónicos, o sea los hegemónicos-y sus consecuencias para el contenido dominante de lo que se difunde, se silencia o se tergiversa; el alarmante predominio de lo conocido como pensamiento único que, aunque con apariencia de una ficción de diversidad mediática, presenta una idea de "realidad" y de sentidos de vida marcadamente coincidente con las propuestas neoliberales, a través de una serie de ideas-fuerza que se enumeran; el notorio reemplazo del "pensamiento crítico" -en el campo comunicológico y en generalpor una aceptación de lo existente, sea de manera directa o a través de posturas pseudo-críticas con base en marcos teóricos hoy de moda (sobre todo de algunas variantes de ese difuso conglomerado conocido como "posmodernismo").

\section{Control de los medios...}

Durante largos años un importante sector de estudiosos de la comunicación y de la realidad política pusieron fuerte énfasis en la importancia que el control y propiedad de los medios y agencias de comunicación tienen para el contenido que se difunde, insistiendo en la inexistencia de neutralidad ideológica y, por el contrario, en la intencionalidad - latente o manifiesta - de transmitir una determinada visión del mundo acorde a sus intereses y propósitos, con plena conciencia del poder de los medios. Infinidad de estudios lo demostraron, teórica y prácticamente, lo que produjo una importante reacción que 
promovió la UNESCO, el proyecto de un Nuevo Orden Informativo Mundial (NOMIC) que, como es ampliamente conocido, tuvo la fuerte oposición de Estados Unidos e Inglaterra, que por ello abandonaron tal institución hasta que el proyecto se retiró de hecho. Eran otros tiempos, con bipolaridad entre potencias mundiales enfrentadas y la presencia de una fuerte rebeldía y protesta que tuvo su apogeo en la década de 1960 y comienzos de la siguiente (con gran influencia en la praxis de sus intelectuales), en que los llamados países del tercer mundo clamaban por sus derechos y planteaban sus denuncias en todos los foros internacionales.

Es innecesario reiterar datos al respecto de sobra conocidos y de los que estaban llenas, en particular en nuestra América Latina, las investigaciones y bibliografía de esa época. Pero es importante recordarlo, para no borrar la memoria histórica y como forma de confrontación con lo que ocurre en una realidad actual muy diferente en los análisis, intereses y búsquedas dentro del campo de la comunicación.

Alrededor de 30 años después, un lapso de tiempo muy grande en esta época de cada vez más rápidos cambios, el panorama es muy diferente: un mundo unipolar con centro en unos Estados Unidos que dominan en todos los terrenos (político, económico, militar), la subordinación de la mayor parte de los países del mundo también en todos los terrenos, la práctica desaparición de la organización (y como instancia activa) de los países del tercer mundo y, como algo fundamental, la hegemonía absoluta de la economía de mercado neoliberal como dogma de casi todos los países y los organismos financieros internacionales con eje en la libertad de comercio. Una "libertad" de modelo económico que, llevada al terreno comunicativo, ha borrado la lucha por el NOMIC, promovida la desaparición (sobre todo en Europa, donde eran dominantes) de los organismos estatales a cargo de emisoras de radio y $\mathrm{TV}, \mathrm{y}$ promovida la privatización de la absoluta mayoría de los canales comunicativos.

Desde una perspectiva formal -y esto lo proclaman sus defensores-, este modelo habría liberalizado el campo de la difusión comunicativa, ahora abierta para quienes quisieran navegar por ellas, rompiendo con el peso del poder estațal o de sus monopolios. Y destacan la amplia gama de opciones que hoy existirían gracias a tal liberalización y al desarrollo tecnológico que la facilita: múltiples emisoras de radio y TV, emisiones satelitales que permiten la llegada al mundo entero con precios no muy altos y accesibles para un porcentaje importante de la población con más de un centenar de opciones (casos de Sky y Direct-TV), infinidad de periódicos y revistas e Internet, ésta última con una libertad prácticamente total para todos los que quieran $6 \mathrm{y}$ puedan) acceder a ella.

Pero iesto es cierto o pasa lo que en muchos lugares, donde se dice que existe algo porque la Constitución y las leyes así lo determinan, confundién- 
dose la realidad con el discurso y la legalidad? ${ }^{2}$ Por supuesto, esta pregunta no es nueva porque siempre se ha planteado, pero en este momento se intensifica ante una realidad bastante diferente y una prédica insistente en tal sentido, con una muy escasa y minoritaria oposición que llega a pocos, los que no se dejan confundir con las apariencias. Porque el campo comunicativo no es - no tendría por qué serlo, sino al contrario- una excepción al conocido proceso de concentración que se produce en el mundo como consecuencia del modelo neoliberal y la llamada "globalización".

Es cierto que Internet - más allá del sistema de espionaje Echelón y los por ahora tibios intentos de censura a ciertos campos como la pornografía infantil, pero que pueden ser anticipos y pruebas de otra mayor (Islas y Gutiérrez, 2002)- sigue estando abierta a quienes pueden acceder a ella (altos sectores en los países ricos occidentales, por ahora muchos menos en los demás, escasísimos en los muy pobres); como también lo es que, en algunos casos, existen medios alternativos que antes no hubiesen podido nacer ni subsistir, sobre todo en los regímenes abiertamente represivos del "socialismo realmente existente" o de las dictaduras latinoamericanas. Pero al menos dos preguntas interrelacionadas son centrales: si las expresiones realmente alternativas pueden acceder a los medios electrónicos, los que realmente llegan a las amplias mayorías; $y$ si pueden verdaderamente competir y enfrentar al que algunos llaman el "pensamiento único" absolutamente dominante, sobre lo que luego se abundará.

Respecto a lo primero, la respuesta es un claro y categórico no, sin necesidad de ninguna demostración, por su clara obviedad, salvo escasísimas excepciones. En cuanto a lo segundo, también es evidente, tal como se planteó en el artículo antes citado, donde se menciona el mantenimiento de las agencias de noticias de siempre, el surgimiento de mega-editoriales y el crecimiento de las fuertes empresas audiovisuales:

Las que no se inscriben en sus esferas de acción tienen un peso cada vez más reducido, y su importancia cuantitativa no puede compararse. ¿Qué puede hacer, por ejemplo y para dar sólo uno local, Radio Educación o la revista Proceso frente a la capacidad de llegada internacional de Time-Warner, $C N N$ o similares, o dentro de México respecto a Televisa o TV Azteca (que, por otra parte, están cada vez más vinculadas - en términos económicos y en contenidos- a empresas transnacionales)?

2. Es muy conocido que hoy existe en el mundo entero un muy alto porcentaje de no credibilidad en las instituciones en general, con marcado alto porcentaje respecto a los políticos, la policía, el Parlamento, la justicia y la vigencia de la democracia. Los fuertes datos presentados en un trabajo anterior (Guinsberg, 2002b), en pocos años han sido superados con creces. 
Sin negar ni el valor ni las significaciones de los medios indicados y muchos otros similares, es evidente que se trata de enanos frente a mega-gigantes transnacionales, causa por la que muchos medios similares son permitidos o tolerados para presentar una imagen de apertura que es sólo formal y limitada por causas evidentes (Guinsberg, 2001a: 70-71).

Se intensifica entonces lo que un estudioso que fue crítico hasta su muerte ya destacó años atrás, cuando el auge de fuerte concentración mediática se iniciaba y no había llegado a los niveles actuales:

Por medio de la expansión, la fusión y la transnacionalización, esas industrias (las productoras de los mensajes y la imaginería, que constituyen la atmósfera cultural nacional e internacional) representan hoy una impresionante concentración de poder cultural e influencia, tanto en Estados Unidos como en el resto del mundo. Además, constituyen un componente cada vez mayor de la economía en general (Schiller, 1992: 109). ${ }^{3}$

A esto debe agregarse lo también conocido de la difusión que tienen estas mega-entidades comunicativas en el mundo entero a través de múltiples filiales, concesiones y canales distribuidores, dominando de manera absoluta el universo audiovisual de noticias, diversiones, etc., y por tanto pasando muy por encima de las producciones nacionales en esos ámbitos, incluso de países del llamado primer mundo, como los europeos. ${ }^{4}$

3. Es importante reiterar que es innecesario ofrecer datos sobre algo muy conocido, al menos por investigadores de la comunicación. De cualquier manera, un breve pero contundente panorama de esta concentración puede verse en un artículo periodístico de hace dos años (Maza, 2000), escrito con base en el libro de Dean Alger, Megamedios. Cómo dominan los medios de comunicación, distorsionan la competencia y ponen en peligro la democracia las corporaciones gigantes. Alli se describen los considerados doce imperios dominantes: Disney Capital Cities-ABC; Time Warner-Turner; News Corporation, de Rupert Murdoch; General Electric-NBC; Bertelsman, de Alemania; Westinghouse-CBS, hoy CBS Inc.; Newhouse-Advanced Publications; Viacom; Microsoft; Matra-Hachette-Filipacchi; Gannett; Tele-Communications Inc. (TCI), coloso de cablevisión; y se describen las propiedades de algunos de ellos (los cuatro primeros). Así, por ejemplo, Time-Warner-Turner incluye múltiples revistas (Times, Sports Illustrated, Fortune, People, Money, Parenting, In Style, Sunset, Healt, Martha Stwart Living, Entertainment Weekly, Teen People, 83,25\% de American Lawyer, 50\% de DC Comics y otra docena); cadenas de televisión (Warner Bros. (WB), la quinta de Estados Unidos; Time Warner Cable, con 12 millones de suscriptores en 1996; canales de televisión por cable como $C N N, C N N$ International, TBS, TNT, Noticiero Headlines, Películas Clásicas Tumer, Cartoon Network, HBO, Cinemax, parte de Comedy Central, Entertainment Network, Canal Sega, Time Warner Sports. A esto se agrega una impresionante lista de radiodifusoras, productoras de cine y TV, editoriales, productoras de discos, Internet y colaterales, equipos y promociones deportivas, conexiones con otras corporaciones de megamedios, y otros que ocuparían un espacio impresionante.

4. “Las prácticas coactivas de los oligopolios de distribución estadounidenses están siempre ahí, sin que las multas del Consejo de Ministros consigan frenarlas. Los canales de televisión, cuando los ciudadanos contemplan sus pantallas tres horas y media diarias, se 
Una muy simple y elemental mirada a las programaciones televisivas y cinematográficas en América Latina y en el mundo en general, muestra claramente el predominio absoluto de Estados Unidos - según los citados conglomerados mediáticos - sobre incluso la suma de las producciones de otras naciones (como ejemplo, véase Sánchez Ruiz, 1998).

Con base en lo anterior, es incuestionable que, sólo como ejemplo, al estilo de muestra representativa, el peso e influencia de las programaciones infantiles vespertinas del canal 11 de México - realizadas con un criterio muy diferente al de la mayoría de fuerte rating - es muy inferior al que produce el alud transnacional citado. $\mathrm{Y}$ así en todo, como se verá más adelante con algunos casos informativos.

Esto no es por supuesto casual, como también ha sido siempre indicado por la corriente crítica de la comunicación. No se trata sólo de la búsqueda de ganancias directas por la comercialización de los productos mediáticos - aunque no son nada despreciables-, sino de aspectos estructurales mucho más importantes: la utilización de los medios como instituciones hegemónicas en el proceso de conformación de los sujetos que posibilitan el mantenimiento y reproducción del sistema de dominación, y el papel actual de los medios (la llamada sociedad de la información) en tarea similar dentro de los procesos económicos, ambas partes profundamente interrelacionadas. Aunque luego se verá algo respecto a lo primero, lo central está desarrollado en trabajos anteriores (Guinsberg, entre otros, 1985, 1988, 1991, 1999, 2002a), por lo que, aunque sea muy someramente sobre lo segundo, no solamente "el sector de la comunicación ocupa ya el lugar central en la economía de Estados Unidos" (Schiller, 1997: 20), sino que una parte del mismo - la informático- es uno de sus ejes estructurales, y la otra se vincula a los objetivos citados antes de la manera que se indica:

La corriente de pensamiento aglutinada en el neoliberalismo actual supone un sistema ideológico de significación y representación de fenómenos de interés social y, simultáneamente, la negación de esa carga ideológica. Y en esta contraposición radica una de las principales fuentes de legitimación del neoliberalismo actual: el carácter meramente técnico de regulación del ciclo económico y aparentemente neutral respecto a los intereses corporativos, sectoriales y de clase social. Como herramienta tecnócrata y equidistante de los agentes implicados, el neoliberalismo contiene una fuerte dosis de persuasión sobre la opinión pública

resisten a dejar de privilegiar las ficciones norteamericanas en su programación. Y el audiovisual europeo, que en las negociaciones del GATT resucitó la fenecida doctrina del NOMIC para defenderse de la colonización cultural por parte del imperio, demuestra su impotencia e hipocresía con la pésima circulación intraeuropea de sus productos. Los alemanes no ven cine español, como los españoles no ven cine alemán. Y este desencuentro se produce en todos los países de la Unión Europea" (Gubern, 1995: 5). 
que tiende a juzgar la gestión positiva y normativa del policy-maker neoliberal como un "sano" ejercicio de objetividad y rigor, al margen de la "contaminación de las ideologías y los valores" (García Menéndez, 1998: 23).

\section{...Control del hombre}

Es de reconocer la alta capacidad del sistema dominante en general de hacer creer las ficciones que lo convalidan frente a las realidades que oculta con ellas. Así como millones creen que Estados Unidos en particular siempre ha sido defensor y paladín de las libertades, la democracia y los derechos humanos en todo el mundo, cuando toda la historia comprueba lo contrario (Guinsberg, 2002e), también ha logrado hacer creer en la absoluta libertad de prensa y en el culto a las diferencias de opinión. Pero si todo lo anterior -el control de propiedad de los grandes medios- muestra categoricamente las consecuentes limitaciones a una libertad de información y de divulgación de las ideas, la proclamada multiplicidad de órganos de difusión ies expresión de respeto a la diversidad de voces y opiniones existente en el mundo actual? Tal existencia numérica es evidente, pero, más allá de que las realmente difundidas están en pocas manos, su alto número no es de por sí garantía alguna de respeto irrestricto a todo tipo de pensamiento según quienes hace años insisten en la existencia de un pensamiento único, algo así como un único contenido reiterado en múltiples variaciones de lo mismo pero con apariencias diferentes que hacen creer en una diversidad y libertad inexistentes.

"En Suecia uno puede ver televisión y hacer zapping entre los diferentes canales, y la impresión es que se trata de la misma película. Veinte canales y todos se ven igual", es la descripción que hace el cineasta Roy Andersson ( $L a$ Jornada, 2001: 17a) - similar a la más literaria de Kundera, transcripta en el artículo anterior ya citado (2001a) - de la teórica que se ha difundido y convertido en postura compartida acuñada por el director de Le Monde Diplomatique:

¿Qué es el pensamiento único? La traducción en términos ideológicos con pretensión universal de los intereses de un conjunto de fuerzas económicas, en particular las del capital internacional. Ha sido, por así decirlo, formulada y definida desde 1994, con ocasión de los acuerdos de Bretton Woods. Sus fuentes principales son las grandes instituciones económicas y monetarias - Banco Mundial, Fondo Monetario Internacional, Organización de Cooperación y Desarrollo Económico, Acuerdo General sobre Tarifas Aduaneras y de Comercio, Comisión Europea, Banco de Francia, etcétera-, que, mediante financiación, vinculan al 
servicio de sus ideas, a través de todo el planeta, numerosos centros de investigación, universidades, fundaciones..., las cuales perfilan y expanden la buena nueva en su ámbito.

Este discurso anónimo es retomado y reproducido por los principales órganos de información económica, y particularmente por las "Biblias" de los inversores y bolsistas - The Wall Street Journal, Financial Times, The Economist, Far Eastern Economic Review, Les Echos, Reuter, etcétera-, propiedad, con frecuencia, de grandes grupos industriales o financieros. Desde diferentes ámbitos, las facultades de ciencias económicas, periodistas, ensayistas, personalidades de la política..., retoman las principales consignas de estas nuevas Tablas de la Ley y, a través de su reflejo en los grandes medios de comunicación, las repiten hasta la saciedad. Sabiendo con certeza que, en nuestras sociedades mediáticas, repetición equivale a demostración (Ramonet, 1998: 15-16, subrayado final mío).

Por supuesto, tal pensamiento único no se expresa sólo, como podría creerse de la lectura del párrafo anterior, en ámbitos o informaciones económicas, sino que se proyecta en todos los terrenos, tanto de la información como en el entretenimiento, como una concepción general acerca de la vida y del mundo: como una ideología, recuperando una terminología que a muchos le molesta por considerar fuera de moda y sin valor. También en textos anteriores (Guinsberg, Matrajt, Campuzano, 2001; Guinsberg, 2002c) se describieron los objetivos y formas de lo que algunos "teóricos" denominan "la otra guerra", es decir la que se libra no con armas bélicas sino por "el control de la mente humana", donde dos de sus principales instrumentos son la presentación de una determinada realidad - la de quienes controlan la información y la difunden de acuerdo a sus intereses-, y la estrategia basada en la "intimidad", que apunta no a la racionalidad sino a la sensibilidad de la imaginación, o sea lo que se ofrece tanto en anuncios publicitarios como en telenovelas, reality shows, diversiones, deportes, concursos, etc., que constituyen el porcentaje fundamental de casi todas las programaciones. ${ }^{5}$

Lo anterior no significa negar la existencia de pensamientos distintos, incluso en medios masivos que podría pensarse que nunca escapan del sistema al que se integran, pero generalmente se trata de planteos marginales en determinadas circunstancias (sobre todo en algunas informaciones y en programas de opinión, éstos últimos casi siempre circunscriptos a receptores más politizados), y sobre todo como algo que hoy difícilmente puede evitarse.

5. En el estudio de esta problemática es importante un libro no precisamente nuevo pero que se mantiene actual, del cual se sacaron informaciones muy valiosas, sobre todo declaraciones de funcionarios de instituciones propagandísticas estadounidenses acerca de los objetivos de éstas y sus manejos (Eudes, 1984). 
Pero, y esto es fundamental, siempre predomina y queda -como lo reconocen muchas teorías comunicológicas - lo que ha sido y es absolutamente dominante en los contenidos que se presentan, en particular aquellos que apuntan a lo indicado, el nivel emocional, que las más de las veces pasa sobre lo intelectual-racional (como saben demasiado bien los especialistas en publicidad y marketing).

Sin pretensiones de un análisis exhaustivo -que debería ser una prioridad para los comunicólogos, aunque no lo hacen, como se verá después-, los siguientes son sólo algunos de los ejes troncales de los actuales contenidos de los medios. Si bien todo ello ya existía previamente, ahora alcanzan una dimensión que los hace muy diferentes:

- La presentación de modelos de vida donde el éxito, el triunfo, la derrota y el fracaso están determinados por la tenencia y uso de mercancías - sin duda la vieja noción de alienación está cada vez más presente y su utilización es más necesaria-, la imperiosa necesidad de competir prácticamente todos contra todos en una lucha social-darwinista, y la baja en las acciones de la idea de solidaridad y vínculos no competitivos. En este sentido, los reality shows ahora de moda no son más que una forma extrema de esta tendencia general al triunfo de uno o de pocos frente a la pérdida de los demás.

- El fomento intensificado a las tendencias individualistas prevalecientes en nuestra época como correlato subjetivo de la economía de mercado, tendencia también apoyada y promovida por algunas posturas del posmodernismo. ${ }^{6}$

- El marcado incremento, cuantitativo y cualitativo, del uso de la violencia como mecanismo de resolución de conflictos y de la búsqueda del triunfo. Una violencia que se estigmatiza en palabras pero que, en un ejemplo más de un ya clásico "doble discurso", es de hecho presentada como vía eficaz y no pocas veces única para el logro de los objetivos buscados, aunque éstos - como en la vida real ocurre con la corrupción, el narcotráfico, la especulación financiera, etcétera- violen normas éticas y morales aceptadas y proclamadas pero que posibilitan el éxito y la obtención de ganancia.

6. Caso, entre otros, de Lipovetzky, pese al claro reconocimiento de sus consecuencia, que de alguna manera resume al señalar que genera "el vacío en tecnicolor" (Lipovetzky, 1988: 10). Un desarrollo mayor sobre tal problemática y las características psico(pato)lógicas de nuestra época en un libro anterior (Guinsberg, 2001). 
- La espectacularización de la realidad, del mundo y de la vida en todos los aspectos, desde una noticia del mundo social hasta incluso (y sobre todo) los más dramáticos, como han sido, entre tantos otros, la "guerra” del Golfo Pérsico, la invasión a Panamá o el atentado a las Torres Gemelas de Nueva York, presentados con "una cobertura planetaria, el show instantáneo con calculada escenografía de guerra y desastre al gustado modo hollywoodense" (Ojarasca, 2001: 2). ${ }^{9}$

- El predominio absoluto de tendencias light y la banalización en prácticamente todo, con muy escasa o incluso nula difusión de otros niveles culturales (algo similar a lo que ocurre de manera dominante en, por ejemplo, la cartelera cinematográfica de la Ciudad de México y en gran parte del mundo).

- La reiteración sistemática, llegándose incluso a la saturación para producir determinados efectos psíquicos y sociales y no sólo por ausencia de otras imágenes, de escenas culminantes de algunos acontecimientos de fuerte peso, como ha sido el impacto de los aviones sobre las Torres Gemelas, los discursos del Presidente Bush, escenas de terror, etcétera, y que ahora se reiteran en la búsqueda de consenso a la probable guerra contra Irak y buscando ocultar las reales causas de ésta.

- El uso creciente y dominante de la mercadotecnia para todo -desde la promoción de mercancías hasta de políticos y sus propuestas-, que reemplaza la discusión de ideas, e incluso justifica algunas líneas de acción (o programas de los medios) en nombre de un muy discutible apoyo cuantitativo de supuestas mediciones.

Gran parte de lo anterior puede sintetizarse en lo que señala un analista respecto a lo que titula como "La neoliberalización del mensaje televisivo" al referirse a algunos cambios producidos hace años en los canales 11 y 13 al incorporar algunas series en su búsqueda de conquista de audiencia.

Al hacerlo, no sólo importaron nueva programación, sino especialmente un nuevo paquete de valores mucho más acordes con lo que es una filosofía neoliberal. Valores tales como "todo se vale", "la astucia debe suplir la experiencia", "lo económico es siempre lo prioritario", "el fin justifica los

7. “Los denominados infoshows yo los denomino infortáculos: acrónimo que surge de información y espectáculo. Dicha modalidad es una renovación de géneros en la cual la información se va convirtiendo en espectáculo, de tal manera que lo que prima al final es el propio espectáculo. Esa vertiente se está desarrollando en algunos programas en los que la audiencia sabe reconocer la posible mezcla para no interpretarlos como simple espectáculo. Lo que me parece inadmisible es que ese tipo de tratamientos se incorporen a los noticiarios, porque en el momento en que se pierde la barrera de diferencia entre lo informativo y el espectáculo, llegamos a la confusión total" (Cebrián, 1997: 37). 
medios", "hay que desconfiar de los otros, hasta que no demuestren lo contrario", "al enemigo siempre hay que aniquilarlo", "la astucia y la audacia son esenciales para triunfar" (Orozco, 1994: 50).

Ubicados en la perspectiva neoliberal - que, en general, y como lo indica el prefijo neo, no hace otra cosa que llevar a posturas extremas posturas previas ya existentes- los medios se ubican, más que antes, en el contexto de la desregulación económica ${ }^{8}$ y de la fuerte competencia por la audiencia y cuotas publicitarias. Como destaca Mattelart, otro de los comunicólogos que no renuncian a la postura crítica:

La idea central es la de la necesidad de dejar actuar a la libre competencia en un mercado libre entre individuos libres de escoger. Esto, explicado a través de los discursos de oposición a la cláusula de exclusión cultural, se ha convertido en: "Dejadles ver lo que quieran. Dejadles apreciar libremente. Confiemos en su buen sentido. La única sanción aplicable a un producto cultural debe ser su éxito o fracaso en el mercado" (Mattelart, 1995: 41-42).

Tal autor comprende que, de tal manera, "la ideología librecambista ha intentado dar carta de naturaleza a su argumentación populista" (ídem.), una de cuyas consecuencias, apoyada por supuesto en la gran liberalización de ideas, ética y normas morales de las últimas décadas del modernismo, es el casi absoluto predominio del rating y, por tanto, de lo que en España se define como "telebasura" o "TV de supermercado" (Azocar, 1993: 66), con todo lo conocido acerca de sus contenidos e intereses. ${ }^{9}$

A partir del 11 de septiembre de 2001 los contenidos de los medios incrementan estas tendencias y a la vez saturan con la ideología de la "lucha contra el terrorismo", pero ahora con niveles de censura que, de hecho, comienzan en la "guerra del Golfo" por la comprensión que se tuvo de las consecuencias que provocó el conocimiento directo de lo ocurrido en Vietnam (masacres, muerte de estadounidenses, etcétera). En otro artículo se analiza con mayor detalle el manejo realizado desde la transmisión directa de los ataques de ese día (Guinsberg, 2002d), mostrándose no sólo la espectacu-

8. Desregulación relativa, porque el poder político sigue teniendo la capacidad de otorgar concesiones para los medios electrónicos —o sea los más importantes en el panorama del homo videns, según la conocida postura de Sartori-, y en muchos países generalmente lo hace, como en México, otorgándolas a grandes cadenas, postergando o impidiendo de esta manera dar voces a sectores diferentes y alternativos.

9. Sin ninguna caída en las conocidas posturas elitistas de no pocos intelectuales que se resisten y niegan a todo contenido popular, ante las programaciones dominantes en la absoluta mayoría de la TV comercial mundial, no es difícil coincidir con lo señalado por un autor que nunca ha caído en tal postura elitista: "En este momento el mejor aliado del neoliberalismo es la televisión privada y pública de América Latina, que es un instrumento de oprobio, extraordinario, y la dosis de estupidización que propone la industria cultural es la mejor manera de complementar al neoliberalismo" (Monsiváis, 1992: 42). 
larización de la presentación de los hechos -en un inicio tal vez comprensible por su sorpresa, impacto y significación-, sino también la inmediata utilización de lo ocurrido para provocar consenso nacional y mundial hacia la política de Estados Unidos en su búsqueda del absoluto control mundial, para lo cual planteó -y continúa haciendo - la religiosa dicotomía entre bien y mal, la intensificación del miedo e inseguridad, y la censura de posturas críticas, buscando no hacerlo por la fuerza sino como autocensura y creando un clima de persecución con acusaciones de falta de patriotismo, etcétera.

Aprovechó para ello lo que la revista Time consideró esos "afortunados y raros momentos históricos" que Estados Unidos "puede moldear al mundo a su antojo" (Reynoso, 2001: 9), ${ }^{10}$ algo fundamental para lo aquí analizado porque, en total acuerdo con la revista británica The Economist, "el éxito en la guerra de propaganda es vital para la preparación de la acción militar" (Jalife-Rahme, 2001: 14). Y esto se presenta desde un primer momento:

Lo que llama la atención en la cobertura de los medios estadounidenses inmediatamente después del 11 de septiembre de 2001, es cómo la historia se repite, y la cobertura mediática fue poderosa desde la perspectiva democrática. Se dio por sentado, casi desde el momento en que se colapsó la torre sur del World Trade Center, que Estados Unidos estaba en guerra, ni más ni menos que en una guerra mundial. La imagen transmitida por los medios fue de un país benévolo, democrático y pacífico brutalmente atacado por terroristas malvados y lunáticos que odian a Estados Unidos por sus libertades y su alto nivel de vida. Estados Unidos tenía que incrementar sus fuerzas militares y ocultas; ubicar a los perpetradores aún vivos y exterminarlos; $y$ en segundo término prepararse para una guerra de largo plazo destinada a extirpar el cáncer del terrorismo global y destruirlo (McChesny, 2001: 6).

Presentación de información-espectáculo prácticamente sin variantes en el mundo entero, con las únicas excepciones de visiones críticas en medios alternativos con una audiencia sin comparación alguna con la predominante, que nuevamente confirma los objetivos indicados sobre los medios como principales instrumentos del control social. Esta tendencia continúa sin visos de terminación al escribirse este artículo (fines de agosto de 2002): se siguen presentando todo tipo de materiales sobre la peligrosidad de Bin Laden y Al Qaeda, al acercarse el primer aniversario de los ataques se continúa con el temor a nuevos ataques, etcétera. En un análisis crítico se indica cómo uno de

10. Este mismo autor destaca la importancia de los editoriales de importantes diarios como The New York Times ("Nadie puede estar al margen de este conflicto") y The Washington Post ("Con serenidad y determinación, la nación se debe preparar para la primera guerra de este nuevo siglo, guerra que debe comenzar por identificar y castigar a los autores del asesinato masivo de ayer, pero que también debe continuar hasta que todas las fuentes de apoyo a los terroristas sean eliminadas"). 
los videos presentados era conocido y de 1998 (aunque se presenta como nuevo), pero por TV no se dijo nada sobre los crímenes de guerra cometidos por la Alianza del Norte afgana en noviembre 2001 mostrados por Newsweek ("No se había leído tanto que recordara con tanta precisión un método muy similar al de los hornos de cremación hitlerianos", escribe Villamil), y en Estados Unidos "se ha pasado a la normalización de la paranoia" (Villamil, 2002: 16). Por otra parte, otro autor crítico escribe algo que confirma lo indicado:

En una información del 15 de agosto publicada por Press Gazette Online, Rena Golden, vicepresidenta ejecutiva y directora general de CNN Internacional, admitió la censura de noticias sobre la guerra de Estados Unidos en Afganistán. Esa censura, explicó, "no fue asunto de presión gubernamental, sino nuestra renuencia a criticar cualquier cosa en una guerra que era obviamente apoyada por la vasta mayoría de la gente".

Como fábricas oficiales de propaganda de la administración Bush, CNN y las otras redes noticiosas corporativas han aceptado obsequiosamente una solicitud de la Casa Blanca de no emitir observaciones de Osama bin Laden sin corregirlas. La Casa Blanca no perdió tiempo en obtener lo mismo de los periódicos en relación con la impresión de transcripciones. "En una maniobra extraña y sin precedentes," señaló Veronica Forwood, presidente de la filial británica de Reporteros sin Fronteras,

las cinco principales redes - CNN, NBC, ABC, CBS y Fox News Channel- se han dado vuelta y han aceptado el llamado a la censura de la consejera de Seguridad del Presidente de Estados Unidos, Condoleeza Rice [...] Afortunadamente, la prensa en Gran Bretaña y en Europa tiene un historial excelente en la cobertura de historias que los medios de EE.UU. han ignorado consecuentemente (y deliberadamente), a pedido del Pentágono y de la administración Bush. Gracias a Internet, esas historias pueden ser leídas por estadounidenses que no tienen acceso a los periódicos extranjeros. Tanto el Guardian como el Independent de Gran Bretaña publican noticias alternativas (disponibles en la red) - y publican también informes y editoriales de periodistas galardonados como Robert Fisk y John Pilger. Esas son historias y opiniones que el New York Times jamás llegaría a tocar (Nimmo, 2002).

Por supuesto, no puede creerse que la siempre conocida deformación de la realidad y los niveles de censura-autocensura son nuevos ni que se limitan a la situación creada en septiembre de 2001: tal problemática ha sido una de las más trabajadas por larguísimo tiempo y existen ríos de tinta al respecto. A ellas debe agregarse la investigación realizada en la Universidad de Guadalajara respecto a los noticieros de Televisa y TV Azteca antes de tales hechos, confirmándose una vez más lo ya harto conocido, tanto acerca de lo indicado como lo aquí planteado, de que la supuesta multiplicidad de voces (muy 
relativa en el caso mexicano) no transmite más que variantes de contenidos similares del pensamiento único hegemónico. ${ }^{11}$

En esta perspectiva, y como parte de tal contexto, no puede dejar de recordarse -por su carácter paradigmático en lo indicado y como reiteración de algo muy conocido en general y en nuestro continente en particular- el papel cumplido por los medios en Venezuela, como vanguardia absoluta en los intentos de derrocamiento del gobierno democráticamente elegido del presidente Chávez. Sobre esto también se ha dicho mucho en los escasos medios alternativos hoy existentes, pero de por sí merecería un análisis particular.

\section{En la búsqueda de la perdida visión crítica de los comunicólogos}

Ya en un artículo citado (2001a) se hizo un extenso análisis del radical y sustantivo cambio producido en estudiosos e investigadores de la comunicación y las características de los trabajos actuales, donde es claramente perceptible una importante pérdida de la visión crítica que se tuvo en épocas anteriores. Aquí no se repetirá, sino que se ampliará lo allí sustentado.

Ya hace varios años Schiller destacó la paradoja de que mientras que los detentadores reales de la autoridad económica y política recurren crecientemente a una u otra forma de comunicación para ampliar o reforzar su influencia, los teóricos actuales que escriben sobre comunicación encuentran que la influencia de los mismos ha sido sobrevalorada (Schiller, 1992: 110), por el resurgimiento de las teorías de los efectos limitados -el poder de los medios resultaría equilibrado por el poder del auditorio- y por la diversidad de imágenes que hoy se ofrecen. Si respecto a esto último ya se vio cómo se trata de algo aparente y no real, es importante ver lo primero por la extrema importancia que en los últimos años se le ha dado al proceso de recepción con base en el reconocimiento de una audiencia activa y no pasiva, como consideraban las teorías conductistas de la "aguja hipodérmica". Tal reconocimiento -indiscutiblemente valioso- hizo que gran parte de las baterías de los comunicólogos se dedicaran a la nueva "moda" y, en muy importante medida, se olvidara la central importancia de los procesos de emisión, como se destacó

11. En esa investigación se concluye que los súper temas de tales noticieros son "Todo está bien", "Allá está peor", "El funcionario es fuente privilegiada de noticias", "Los televidentes sólo son espectadores", y "Las declaraciones de funcionarios son hechos" (Orozco Gómez y Medina Jackson, 2000: 76-79). Si bien ello sigue siendo cierto, debe reconocerse que en los últimos años, aunque de manera no tan alta como muchos quieren creer o hacer creer, existe alguna apertura a otras posturas. 
en su momento (Guinsberg, 1990, 1998), y que Schiller (1992) y otros autores mostraran como una de las razones para devaluar el impacto de los medios: el público puede cambiar de canal o leer otros diarios, le da significado a lo que recibe, se enfatiza el carácter "subversivo" y de "resistencia" del espectador, etcétera, por lo que este autor, en diferentes párrafos, señala a veces con ironía:

iQué reconfortante para los fabricantes de mensajes culturales descubrir que no existe el imperialismo cultural! Cada auditorio recibe su propio mensaje [por lo que] Liebes concluye: "La idea de un simple mensaje 'norteamericano', que es mucho más satisfactorio que nos digan que nosotros tenemos el poder, a tener que luchar por conquistarlo en contra de formidables enemigos (p. 135).

Otra de las aparentes ventajas de la hipótesis del auditorio activo es su indiscutible aseveración de que la sociedad occidental, y Estados Unidos en particular, no es una sola masa homogénea sino un agregado de innumerables grupos y subgrupos. Sin negar esta evidente situación, la existencia de una multitud de diferentes agrupaciones sociales difícilmente es prueba de un gobierno democrático, o de la difusión del poder en la sociedad general. iMuy al contrario! Sin importar la historia y experiencia de cada uno de los subgrupos, todos se hallan bajo el dominio de las fuerzas del mercado y el capital que controla esas fuerzas. Es el gran común denominador que asegura la desigualdad básica en el orden social, una desigualdad que los pluralistas y los culturalistas del auditorio activo con demasiada frecuencia ignoran (p. 137).

Reconoce, por supuesto, que "el auditorio sí cuenta, pero no en la forma en que la teoría del auditorio activo lo explica" (p. 135), de manera coincidente a la de A. Mattelart (1995: 42):

Pero este retorno a un receptor mediático activo tiene también su lado perverso ya que, al focalizar unilateralmente la libertad del consumidor para decodificar los programas y otros productos culturales, vengan de donde vengan, permite deshacerse a buen precio de las cuestiones sobre la desigualdad de los intercambios y la necesidad de elaborar políticas nacionales y comunitarias sobre un mercado de flujos que sigue siendo profundamente desigual.

Puede verse que de esta manera - aunque debe quedar claro que no todos los estudiosos de las audiencias activas caen en esta postura-, de hecho, aunque no se diga explícitamente, se desvaloriza y a veces niega la importancia de los aspectos políticos y económicos de los medios, convirtiendo al proceso comunicativo en un fenómeno psicológico individual o cuanto más grupal. Y es precisamente eso lo que busca el poder y que aceptan no pocos comunicólogos, hoy tal vez una mayoría -en consonancia con el "espíritu" de nuestra época-, sea de manera manifiesta o a través de subterfugios intelec- 
tuales escapistas y/o de presunta oposición genérica y abstracta, tal como se escribió en el anterior artículo (2001a) donde, según otro autor:

Asistimos a un singular contraste entre una apelación discursiva a la radicalidad, y un contenido de textos que poco tiene que ver con ella... Se ha logrado por esa vía la curiosa operación de afirmar que se habla de política, sin hablar de política en serio, ni retar al poder de alguna manera (Follari, 2002: 130 y 137).

En realidad éste último plantea tal crítica no a los comunicólogos sino a los estudios culturales, campo últimamente muy aceptado por aquellos y hoy dominante en la disciplina, considerando que en tal escuela (y en la aceptación de la corriente derridiana) se produce la "progresiva literaturización de las ciencias sociales" (p. 8) y desaparece lo socioeconómico, en aras de lo cultural o de lo lingüístico. Todo se transforma en textual, y en consecuencia aún las relaciones de propiedad e interés económico sobre las que se establece la circulación de información, se borran casi por completo de los análisis. El tema del poder se va evaporando en cuanto a que sea trabajado con pertinencia y precisión, aunque se lo mencione a raudales y —en jerga supuestamente foucaultiana- se lo encuentre por todas partes, lo cual es equivalente a que no esté específicamente en ninguna. La política brilla por su ausencia, aunque también se pretenda conjurarla con pases de magia retóricos y altisonantes (p. 9).

Y lo que considera ha sido un avance teórico al incluir temas y perspectivas antes poco o nada vistos en la especificidad comunicativa,

constituye inevitablemente a la vez un 'retroceso': los temas principales de la política han quedado opacados, el Estado ha pasado a ser considerado como escasamente relevante, incluso en dimensiones en las cuales su influencia sigue siendo decisiva (p. 127).

Por supuesto, esta tendencia no se da en todos sus seguidores, ni en la misma dimensión, pero es algo que debe señalarse y que ratifica lo señalado sobre los mismos en el trabajo anterior antes citado. ${ }^{12}$

En este contexto generalizado de los actuales estudios e investigaciones en comunicación, puede parecer una exageración que se diga que sus integrantes, "en aras de adaptarnos a la 'modernidad' hemos entendido todo menos la comunicación, especialmente la social" (Esteinou, 1994: 7), pero todo lo sustentado en este texto y por los comunicólogos críticos que subsisten indican que no lo es.

12. Lo anterior es sólo una de las críticas que tal autor formula a los estudios culturales en general y a algunos de sus autores en particular, con base en una discusión epistemológica que no es el tema de este artículo. 
Una verdadera lástima, porque la importancia de los medios -fundamental en todos los terrenos e incluso mayor a la que siempre fue-requiere de la visión y el andamiaje crítico que existieron en otros momentos y que hoy, como ya se repitió múltiples veces, se encuentran muy debilitados.

Y si a los marcos teóricos de la comunicación crítica hegemónica décadas atrás se le pueden, y deben, hacer muchos cuestionamientos, también críticos, su superación no se logra precisamente con su abandono, como ocurre actualmente.

\section{Bibliografía}

Andersson, R. (2001), México, La Jornada, 8 junio.

Azocar, P. (1993), “España: 'telebasura' y TV de supermercado", en Chasqui, Quito, CIESPAL, núm. 47.

Cebrián, M. (1997), "El neoliberalismo conduce a desviaciones éticas. El manejo espectacular de la información en TV", en Revista Mexicana de Comunicación, núm. 49.

Eco, U. (1977), Apocalípticos e integrados, 5ª edición, Barcelona, Lumen.

Esteinou, L. (1994), "Recrear la comunicación y aliviar la soledad de masas", en Comunicación Media, México, núms. 10-11.

- (2001), "El olvido de Armand Mattelart por la academia de comunicación mexicana", en B. Solís Leree (edit.), Anuario de Investigación de la Comunicación VII, México, Coneicc/UAM-Xochimilco, pp. 33-64.

Eudes, Y. (1984), La colonización de las conciencias, México, Gustavo Gili.

Follari, R. (2002), Teorías débiles (para una crítica de la deconstrucción y de los estudios culturales), Rosario, Homo Sapiens.

García Menéndez, J. (1998), "Neoliberalismo: sofisma científico y fascinación comunicativa", en Chasqui, Quito, CIESPAL, núm. 62.

Gubern, R. (1965), "El desencuentro audiovisual", en Boletín Fundesco, Madrid, núm. 162.

Guinsberg, E. (1985, 1988, 2002a), Control de los medios, control del hombre. Medios masivos y formación psicosocial, México, Nuevomar ( $1^{\text {a }}$ ed.), Pangea-UAM-X ( $2^{\mathbf{a}}$ ed.), Plaza y Valdés ( $3^{\underline{a}}$ ed.). (1990), "Necesidad y riesgos del estudio del momento de la recepción", en Telos, Madrid, Fundesco, núm. 24, pp. 10-11.

- (1991), “En la búsqueda de nuevos paradigmas para el estudio de la comunicación?", en Comunicación y Sociedad, Guadalajara, Universidad de Guadalajara, núms. 10-11, pp. 51-84. 
(1997), “La 'fábrica de sueños' en nuestros tiempos posmodernos y neoliberales”, en Subjetividad y Cultura, México, núm. 9, pp. 77-81.

(1998), "Placer y deseo en los procesos de recepción. Una aproximación psicoanalítica”, en Comunicación y Sociedad, Guadalajara, Universidad de Guadalajara, núm. 33, pp. 205-230.

— (1999), "Televisión y familia en la formación del sujeto", en J. C. Lozano y C. Benassini (ed.), Anuario de Investigación de la Comunicación $V$, México, Coneicc-Universidad Iberoamericana, pp. 31-54.

- (2000a) "La inseguridad en y de nuestra cultura", en Anuario de Investigación 1999, México, pp. 71-87, Departamento Educación y Comunicación, UAM-X.

— (2000b), “Televisión y violencia”, en H. Kurnitzky (comp.), Globalización de la violencia, México, Colibrí, pp. 183-201, 232-236.

— (2001a), "Los estudios e investigaciones en comunicación en nuestros tiempos neoliberales y posmodernos", en B. Solís Leree (ed.), Anuario de Investigación de la Comunicación VI, México, Coneicc-UAM-Xochimilco, pp. 65-94.

- (2001b), La salud mental en el neoliberalismo, México, Plaza y Valdés. (2002b), El malestar en la cultura en América Latina, tesis de Doctorado en Estudios Latinoamericanos, Facultad de Ciencias Políticas y Sociales, UNAM.

(2002c), "La otra guerra: los medios y el control "de las conciencias", en N. M. Maldonado Reynoso (coord.), Horizontes comunicativos en México. Estudios críticos, México, Asociación Mexicana de Investigadores de la Comunicación (AMIC), pp. 135-153.

- (2002d), "Control social en 'tiempos de guerra", en Anuario de Investigación 2001, México, Departamento Educación y Comunicación, UAMXochimilco.

(2002e), "Democracia y derechos humanos en el neoliberalismo", en Letras de Obsidiana, Puebla, Universidad Iberoamericana, núm. 2, pp. 5-19.

- y Matrajt, Campuzano (2001), "Subjetividad y control social: un tema de hoy y siempre”, en Subjetividad y Cultura, México, núm. 16, pp. 7-26.

Jalife-Rahme, A. (2001), "Terrorismo desinformativo", en Revista Mexicana de Comunicación, México, núm. 72.

Islas, O. y F. Gutiérrez (2002), "El Gran Hermano Gates te vigila”, en Revista Mexicana de Comunicación, México, núm. 78.

Lipovetzky, G. (1988), La era del vacio. Ensayos sobre el individualismo contemporáneo, $3^{\text {a }}$ ed., Barcelona, Anagrama. 
Mattelart, A. (1995), "Los nuevos escenarios de la comunicación internacional", en Revista Mexicana de Comunicación, México, núm. 40, pp. 38-42.

McChesney, R. (2001), "Entre el 'patriotismo' y la libertad de información”, en "Masiosare", suplemento de La Jornada, México, núm. 207, 9 de diciembre.

Maza, E. (2000), "Las megafusiones de la comunicación: el mundo bajo control”, en Proceso, México, núm. 1227, 7 de mayo.

Monsiváis, C. (1992), "Entrevista con María Elena Montoya Vélez", en La Jornada Semanal, México, núm. 170, 13 de septiembre.

Nimmo, K. (2002), "La conversión de CNN a la condición de perro faldero", en: www.rebelion.org, 26 de agosto.

Ojarasca (2001), "Presentación”, en Ojarasca, núm. 53, suplemento de $L a$ Jornada.

Orozco Gómez, G. (1994), “La neoliberalización del mensaje televisivo”, en Revista Mexicana de Comunicación, México, núm. 33.

— y Medina Jackson, D. (2000), "Súper temas noticiosos en la televisión mexicana. Análisis de la información en los noticiarios $24 \mathrm{Horas}$ y $\mathrm{He}$ chos", en Comunicación y Sociedad, Guadalajara, Universidad de Guadalajara, núm. 37 , pp. 53-86.

Ramonet, I. (1998), "El pensamiento único", en Le Monde Diplomatique, edición española: Pensamiento crítico vs. Pensamiento único, Madrid, Temas de Debate.

- y Reynoso, R. (2001), "Del terror informativo a la propaganda belicista", en Revista Mexicana de Comunicación, México, núm. 72.

Sánchez Ruiz, E. (1998), "Cine y globalización en México", en Comunicación y Sociedad, Guadalajara, Universidad de Guadalajara, núm. 33.

Sartori, G. (1998), Homo videns. La sociedad teledirigida, Madrid, Taurus.

Schiller, H. (1992), “iA quién pertenece el poder de los medios? Una concepción cambiante", en Comunicación y Sociedad, Guadalajara, Universidad de Guadalajara, núms. 14-15, pp. 109-142.

— (1997), "La comunicación, un asunto de Estado para Washington", en Le Monde Diplomatique, México, núm. 3.

Villamil, J. (2002), "Propaganda para ocultar crímenes de guerra", en La Jornada, México, 25 de agosto. 